\title{
Hiperfosfatasemia benigna transitoria de la infancia: una entidad a tener en cuenta
}

\author{
MR.García Luzardo, N. Rodríguez Calcines, E. Colino Gil \\ Hospital Universitario Materno-Infantil de Canarias. \\ Las Palmas de Gran Canaria. Gran Canaria. España.
}

\begin{abstract}
Resumen
La hiperfosfatasemia transitoria benigna infantil (HTBI) es una entidad en la que se observan marcadas elevaciones de fosfatasa alcalina sérica, sin evidencia clínica, bioquímica ni en exámenes complementarios de patología ósea, hepática, renal o endocrinometabólica.

Se presenta el caso de una paciente de ocho meses ingresada por un cuadro febril y elevación importante de fosfatasa alcalina.

La HTBI es una entidad frecuente que debe tenerse en cuenta para evitar preocupaciones y exploraciones innecesarias. Si un paciente tiene elevación de fosfatasa alcalina, con exploración física, calcio, fosfatos y perfil hepático normales, se le debe controlar clínicamente y continuar midiendo los niveles de fosfatasa alcalina hasta la normalización. Si persiste elevada tras tres meses, debería investigarse el origen de las isoenzimas y estudiar a familia.
\end{abstract}

Palabras clave: Hiperfosfatasemia. Fosfatasa alcalina.

Benign transient hyperphosphatasemia of infancy: a condition to be considered

Abstract

Benign transient hyperphosphatasemia of infancy (BTHI) is a condition where disproportionately high levels of serum alkaline phosphatase are observed, without clinical or biochemical evidence of bone, liver, renal or metabolic disease.

We report a case of an eight months old patient presenting with fever and important increase of serum alkaline phosphatase.

The HTBI is a frequent entity to be considered in order to avoid unnecessary investigations. If a patient has high alkaline phosphatase level, with physical examination, calcium, phosphate and liver normal profile, he/her should be monitored clinically and by measuring alkaline phosphatase levels until normalization. If high level persists after 3 months, the origin of the isoenzymes and a family study should be investigated.

Key words: Hyperphosphatasemia. Alkaline phosphatase.

María del Rosario García Luzardo, saragarlu@telefonica.net

Los autores declaran no presentar conflictos de intereses en relación con la preparación y publicación de este artículo. 


\section{Introducción}

La fosfatasa alcalina (FA) es una enzima de membrana distribuida en diferentes órganos; existen diversas isoenzimas con propiedades catalíticas similares pero genéticamente distintas. En adultos, las isoenzimas hepáticas y óseas constituyen más del $90 \%$ de la fosfatasemia, siendo la relación entre ambas de 1:1; en niños, habitualmente el $85 \%$ de la FA es ósea y el $15 \%$ hepática ${ }^{1-3}$.

La elevación de FA en sangre puede deberse al consumo de fármacos o a afecciones hepatobiliares, endocrinometabólicas u óseas con recambio óseo aumentado, aunque también existen situaciones fisiológicas, como el embarazo, el crecimiento o la vejez, donde pueden producirse incrementos séricos de esta enzima ${ }^{1,3,4}$.

\section{Caso clínico}

Se presenta el caso de una paciente de ocho meses de edad ingresada por un cuadro de siete días de evolución consistente en fiebre hasta de $40{ }^{\circ} \mathrm{C}$, rechazo de la ingesta y vómitos. No tenía antecedentes familiares ni personales patológicos de interés, ni alergias conocidas. En la exploración física solo destacaban pequeñas adenopatías laterocervicales rodaderas e hiperemia faríngea.
En el estudio complementario solicitado, tenía un hemograma con velocidad de sedimentación globular normal; proteína $\mathrm{C}$ reactiva, $4,48 \mathrm{mg} / \mathrm{dl}$; y sodio, potasio, cloro, magnesio, calcio (Ca), fósforo $(P)$, bilirrubina, proteínas y gasometría normales. Los cultivos de sangre, orina y heces fueron negativos $y$ en el frotis faríngeo se aisló Parainfuenzavirus 3.

Un hallazgo analítico que llamó la atención fue una cifra de FA de 5252 UI/I. Se preguntó nuevamente a los padres en busca de alguna causa de esta elevación de FA, con especial insistencia en el consumo de fármacos, antecedentes de fracturas o enfermedades previas, tanto en la paciente como en sus familiares, sin obtener nuevos datos.

Se solicitó nuevamente una determinación de FA para comprobar que no fuese un error de laboratorio, así como de GGT, vitamina $D$, hormona paratiroidea (PTH) e isoenzimas de FA. En esta analítica se confirmó la elevación de FA (6070 UI/I), resultando el resto de parámetros solicitados (GGT, isoenzimas de FA, vitamina $D$ y $P T H$ ) normales.

Al séptimo día de ingreso, una vez solucionado el proceso febril, se procedió al alta con el diagnóstico de infección por Parainfuenzavirus 3 e hiperfosfatasemia en estudio. Se controló clínicamente y con determinaciones periódicas de FA en consultas externas. 
Figura 1. Niveles séricos de fosfatasa alcalina en la paciente durante el seguimiento FA (UI/I).

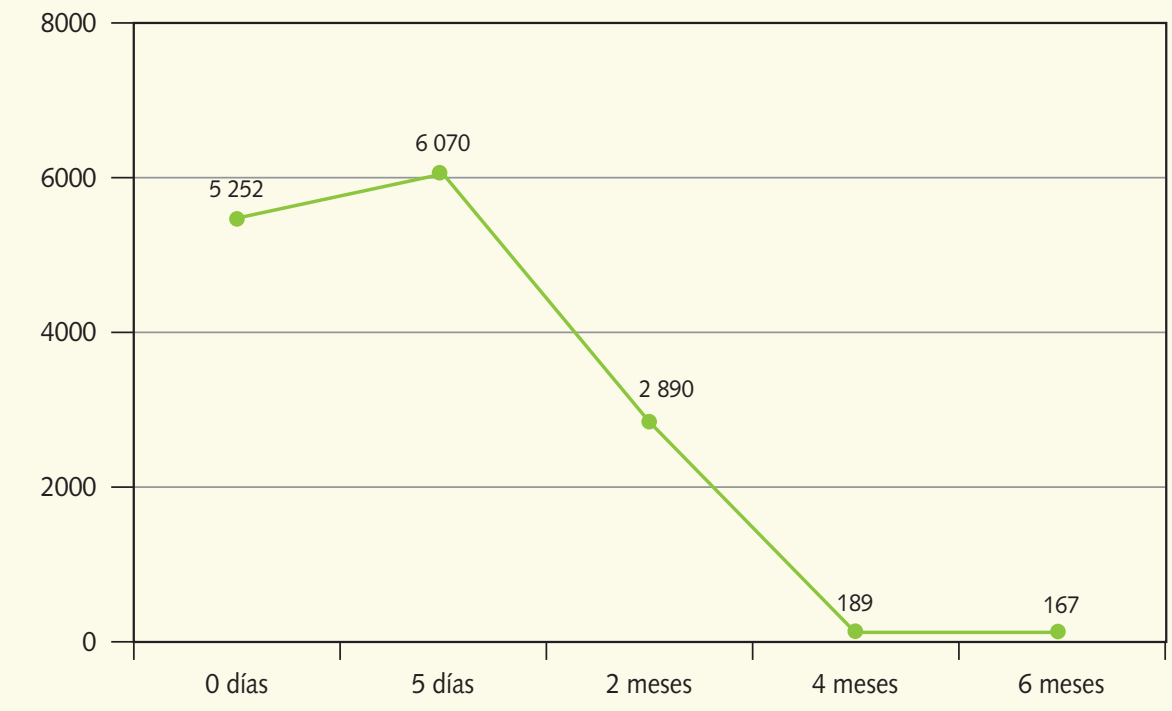

FA: fosfatasa alcalina; UI/l: unidades internacionales por litro.

En los controles posteriores presentó un descenso progresivo de FA (figura 1), permaneció asintomática y con exploración física rigurosamente normal, por lo que se procedió al alta definitiva a los seis meses, tras presentar dos determinaciones de FA dentro de los valores normales para su edad, con el diagnóstico de hiperfosfatasemia benigna transitoria de la infancia (HTBI).

\section{Comentarios}

La HTBI es una entidad en la que se observan marcadas elevaciones séricas de $F A$, sin evidencia clínica, bioquímica, ni en estudios complementarios de patología ósea, hepática, renal o endocrino-metabólica ${ }^{3-5}$.

Fue descrita inicialmente por Bach en 1954; en 1977 Posen le da el nombre de hiperfosfatasemia transitoria de la infancia y en 1985 Kraut define los criterios diagnósticos que siguen vigentes en el momento actual (tabla 1) 1,6. $^{4}$.

Es la causa más frecuente de aumento de FA en la infancia, con una incidencia de aproximadamente 1/2000 pacientes/año en el ámbito hospitalario, aunque probablemente esta estimación sea menor a la real. No parecen existir dife- 
Tabla 1. Criterios diagnósticos de hiperfosfatasemia benigna transitoria de la infancia (Kraut, 1985)

- Edad menor de cinco años

- Sintomatología variable

- Ausencia de signos clínicos de enfermedad ósea y/o hepática

- Ausencia de signos biológicos de enfermedad ósea y/o hepática

- Análisis isoenzimático que muestra una elevación conjunta de las fracciones ósea y hepática de movilidad ligeramente alterada

- Normalización en menos de cuatro meses

rencias entre sexos, predomina en los meses fríos y en los primeros años de vi$\mathrm{da}^{4,5,7,8}$. Según los expertos, valores de la enzima superiores a seis veces el límite superior de normalidad para la edad, junto con un patrón enzimático característico, tienen un $95 \%$ de probabilidad de ser $\mathrm{HTB}^{13}$.

El mecanismo por el cual se eleva la FA permanece sin aclarar, aunque se han sugerido diferentes teorías, las más aceptadas son la destrucción celular, el aumento de síntesis intracelular por estrés celular, la ruptura del anclaje de la enzima a la membrana celular, la disminución del aclaramiento de la enzima circulante (por sialización de la FA se genera la isoenzima liver-like típica con menor aclaramiento hepatobiliar. Es la hipótesis más aceptada) o bien la activación de la enzima circulante ${ }^{3,5}$.
Esta entidad es un proceso benigno $y$ autolimitado, sin secuelas a largo plazo. Se ha asociado a un gran número de entidades, especialmente infecciones virales de vías aéreas y gastrointestinales, aunque también ocurre en pacientes sanos $^{2-5,79-13}$.

Ante un paciente con elevación de FA, exploración física, $\mathrm{Ca}$, $\mathrm{P}$ y perfil hepático normales, se aconseja controlar clínicamente y solicitar FA periódicamente; si persiste elevada tras 3-6 meses, debe estudiarse el origen de las isoenzimas y a la familia, por si fuese una hiperfosfatasemia benigna familiar, 1,3,4,10.

Para concluir, conviene recordar esta entidad en el proceso diagnóstico de los niños con elevación de FA, sin convertirla en un diagnóstico de exclusión; evitando así preocupaciones y exploraciones innecesarias. 


\section{Bibliografía}

1. Navarro Despaigne D, Moro Álvarez MJ, Díaz Curiel M. Hiperfosfatasemia familiar. Presentación de un caso y consideraciones diagnósticas. An Med Intern. 2007;24(8):387-9.

2. Wolf PL. The significance of transient hyperphosphatasemia of infancy and childhood to the clinician and clinical pathologist. Arch Pathol Lab Med. 1995;119:774-5.

3. Pace $A E$, Osinde ME. Hiperfosfatasemia transitoria benigna de la infancia. Una aproximación diagnóstica racional. Arch Argent Pediatr. 1999; 97:383-90.

4. Melo M, Bustani Carneiro N, Tolaymat N, Paes FN, Bittencourt CN, Rui Diniz-Santos D et al. Hiperfosfatasemia transitória benigna na infancia. Rev Cienc Méd Biol. 2004;3(1):108-14.

5. Diego Núñez MA, González Menéndez A, García Díez B. Hiperfosfatasemia transitoria de la infancia. Nueve casos y revisión de las aportaciones españolas. An Esp Pediatr. 1997;46:503-7.

6. Kraut JR, Metrick M, Maxwell NR, Kaplan $M M$. Isoenzyme studies in transient hyperphosphatasemia of infancy. Ten new cases and review of the literature. Am J Dis Child. 1985;139:736-40.
7. Garrote de Marcos JM, Molina Arias M, Echávarri Olavarría F, Arregui Sierra A. Hiperfosfatasemia transitoria benigna: aportación de 20 nuevos casos. An Esp Pediatr. 1996;44:112-6.

8. Behúlova $D$, Bzdúch $V$, Holesova $D$, Vasilenková A, Ponec J. Transient hyperphosphatatasemia of infancy and childhood; study of 194 cases. Clin Chem. 2000;46:1868-9.

9. Ferrándiz Santos J, Navarro Falcones C, Gutiérrez Juáez J, Tabernero Carrascoso M. Hiperfosfatasemia transitoria de la infancia: aportación de cinco nuevos casos. An Esp Pediatr. 1992;37:417-8.

10. Riaño Galán I, Rey Galán C, Blanco Joglar J, Humayor Yáñez J, Vargas Zúñiga F. Hiperfosfatasemia transitoria de la infancia: dos nuevos casos a una edad inusual. An Esp Pediatr. 1993;38:370-1.

11. Bonjoch Marí C, Roger Azemar M, Viñallonga Sardà X. P-11. Hiperfosfatasemia transitoria de la infancia. A propósito de dos casos. Rev Pediatr Aten Primaria. 2009;11(Supl 17):e46.

12. Casaní Martínez C. Hiperfosfatemia transitoria de la infancia: un nuevo caso. Rev Pediatr Aten Primaria. 2007;9:449-53.

13. de Diego Núñez MA. Hiperfosfatasemia transitoria de la infancia: actualización. Rev Pediatr Aten Primaria. 2008;10:173-4. 